\title{
Rede neural artificial aplicada à previsão de vazão da Bacia Hidrográfica do Rio Piancó
}

\author{
Wanderson dos S. Sousa $^{1}$ \& Francisco de A. S. de Sousa ${ }^{1}$
}

\begin{abstract}
RESUMO
A previsão de vazão em um sistema hídrico não é apenas uma das técnicas utilizadas para minimizar o impacto das incertezas do clima sobre o gerenciamento dos recursos hídricos mas, também, um dos principais desafios relacionados ao conhecimento integrado da climatologia e da hidrologia de uma bacia hidrográfica. O objetivo deste trabalho foi modelar a relação não-linear entre chuva e vazão na bacia hidrográfica do rio Piancó, no semiárido paraibano, através da técnica de Redes Neurais Artificiais (RNA). Aqui se avaliou a capacidade da RNA modelar o processo chuva-vazão em base mensal e se considerou, durante o seu treinamento, a influência da arquitetura da rede e da inicialização dos pesos. No final do treinamento foi escolhida a melhor arquitetura para modelar vazões médias mensais na bacia estudada, com base no desempenho do modelo. A arquitetura de RNA que produziu melhor resultado foi a RC315L, com valores para o coeficiente de determinação, de eficiência e erro padrão da estimativa de 92,0, 77,0\% e 8,29, respectivamente.
\end{abstract}

Palavras-chave: hidrometeorologia, processo estocástico, processo chuva-vazão

\section{Artificial neural network applied to the forecast of streamflow in the Piancó River Basin}

\begin{abstract}
Streamflow forecasting in a water system is one of the techniques used to reduce the impact of the uncertainties of the climate on administration of the water resources. That technique can be considered as one of the principal challenges related to the integrated knowledge of the climatology and of the hydrology of the river basin. The aim of this work was to model the non-linear relationship between rainfall and streamflow in the Piancó River Basin, in the Paraíba semiarid, using the technique of Artificial Neural Networks (ANN). Here the ability of ANN was evaluated to model the rainfallrunoff process on a monthly basis. During training of the ANN, the network architecture and weights initialization influence were considered. At the end of the training the best architecture was chosen, to model the streamflow monthly mean in the studied basin, based upon the performance of the model. The ANN architecture that produced the better result was RC315L with values for the determination coefficient, efficiency coefficient and standard estimate error (SEE) equal to $92.0,77.0 \%$ and 8.29 respectively.
\end{abstract}

Key works: hydrometeorology, stochastic process, rainfall-runoff process 


\section{INTRODUÇÃO}

Nos últimos anos, o aumento da população, a necessidade de alimentos e energia e o crescimento da atividade industrial, têm aumentado significativamente a demanda por água. $\mathrm{O}$ atendimento a esta demanda constitui um dos problemas mais importantes em muitas partes do mundo; agravando a situação, os mecanismos climáticos que produzem as precipitações no semiárido são complexos, sobretudo quando aliados a fatores, como orografia da região, sistemas atmosféricos de meso e grande escalas e a proximidade do mar, resultam em forte variabilidade espaço-temporal das precipitações que podem gerar eventos extremos, como grandes cheias ou secas devastadoras. Felizmente, hoje já existe a possibilidade de se prever as probabilidades de ocorrência de eventos extremos e os períodos em que, provavelmente, ocorrerão. Essas informações podem ser usadas para minimizar os efeitos negativos desses eventos.

A previsão de vazão em um sistema hídrico é uma das técnicas utilizadas para minimizar o impacto das incertezas do clima sobre o gerenciamento dos recursos hídricos podendo-se considerá-la um dos principais desafios relacionados ao conhecimento integrado da climatologia e hidrologia. A utilização de vazões previstas para a otimização de operação de reservatórios é sugerida por muitos autores (Hamlet et al., 2002; Barros et al., 2003; Tucci et al., 2003).

Atualmente, muitos modelos hidrológicos estão sendo utilizados em estudos ambientais, modelos distribuídos ou concentrados, conceituais ou empíricos, discretos ou contínuos. O objeto de estudo da maioria desses modelos é a bacia hidrográfica, em virtude da simplicidade que oferece na aplicação do balanço hídrico (Villela \& Mattos, 1975). O modelo de Rede Neural Artificial (RNA) foi escolhido dentre os vários modelos existentes por ser um modelo empírico que tem sido amplamente aceito como forma potencialmente útil de se modelar sistemas não-lineares complexos com grande quantidade de dados. Esses modelos são particularmente úteis em situações nas quais as relações dos processos físicos ainda não são completamente compreendidas. Os modelos RNAs podem, ainda, substituir os modelos matemáticos e estatísticos convencionais ou se associar a eles.

Favoreto et al. (2001) mencionam que uma das áreas promissoras para grande aplicabilidade das redes neurais artificiais é a previsão de séries hidrológicas, vazão e precipitação, nos seus mais diferentes usos. Santos \& Pereira Filho (2003) apresentam alguns resultados que mostram a potencialidade da técnica.

Vários autores realizaram estudos usando RNAs com a finalidade de modelar o processo chuva-vazão (Sarle, 1994; Flood \& Kartam, 1994; Elshorbagy et al., 2000; Ramos \& Galvão, 2001; Lima \& Ferreira Filho, 2003; Olivo et al., 2002; Muller \& Fill, 2003; Almeida \& Barbosa, 2004; Sousa \& Sousa, 2006), sendo que todos encontraram resultados satisfatórios, inclusive melhores que os obtidos com outros modelos hidrológicos.

O objetivo deste estudo foi propor um modelo baseado em técnicas de redes neurais artificiais que sirva para simular e prever vazões médias mensais na estação fluviométrica lo- calizada na cidade de Piancó, no semiárido paraibano, o que será possível a partir da elaboração de várias arquiteturas de RNA com base em dados de precipitação média mensal, a montante dessa estação envolvendo, portanto, parte da bacia hidrográfica do rio Piancó.

Apesar da metodologia, RNA, não ser recente, ainda assim deverá contribuir como nova forma de abordagem de previsão hidrológica em bacias hidrológicas localizadas em regiões semiáridas, com poucas disponibilidades de dados e de características físicas da bacia hidrográfica.

\section{MATERIAL E MÉTODOS}

\section{Área de estudo}

O estudo foi desenvolvido para a Bacia Hidrográfica do Rio Piancó, localizada no sudoeste do Estado da Paraíba, fronteira com o Ceará a oeste e com Pernambuco, ao sul. O acesso a partir de João Pessoa, capital do Estado da Paraíba, é feito através da BR-230 até a cidade de Patos; em seguida, acessa-se a BR-361 e se percorre cerca de $80 \mathrm{~km}$, totalizando uma distância de 391,9 km da capital.

Em termos climatológicos, a bacia hidrográfica está inserida no denominado "Polígono das Secas", constituindo um tipo semiárido quente e seco, segundo a classificação de Koppen. As temperaturas são elevadas durante o dia, amenizando à noite, com variações anuais dentro de um intervalo 23 a $30{ }^{\circ} \mathrm{C}$, com picos ocasionais mais elevados, principalmente durante a estação seca. O regime pluviométrico além de baixo é irregular, com médias anuais de $751,1 \mathrm{~mm} \mathrm{ano}^{-1}$ com mínimas e máximas de 180,0 e 1511,8 $\mathrm{mm}^{-1}$ ano $^{-1}$; no geral, caracteriza-se pela presença de apenas duas estações: a seca, que constitui o verão, cujo clímax é de setembro a dezembro, e a chuvosa, denominada, pelo sertanejo, de inverno, restrito a um período de 3 a 4 meses por ano. A umidade relativa do ar média anual varia de 64 a $72 \%$; por outro lado, merece registro a variação da insolação diária durante o ano, que alcança uma média de 7,3 a 8,7 h dia-1.

A vegetação é de pequeno porte, típica de caatinga xerofítica, onde se destaca a presença de cactáceas, arbustos e árvores de pequeno a médio portes; os solos são resultantes da desagregação e decomposição das rochas cristalinas do embasamento sendo, em sua maioria, do tipo Podizólico Vermelho-Amarelo de composição arenoargilosa, tendo-se localmente Latossolos e porções restritas de solos de aluvião. A rede de drenagem é do tipo intermitente e seu padrão predominantemente dentrítico; devido à existência de fraturas geológicas, mostra variações para retangular e angular.

Todo este complexo abrange, completa ou parcialmente, os municípios de Água Branca, Aguiar, Boa Ventura, Catingueira, Conceição, Coremas, Curral Velho, Diamante, Emas, Ibiara, Igaracy, Imaculada, Itaporanga, Juru, Manaíra, Nova Olinda, Olho D’Água, Pedra Branca, Piancó, Pombal, Princesa Isabel, Santana dos Garrotes, Santana de Mangueira, São José de Caiana, Serra Grande e Tavares, ocupando uma área aproximada de $9.274,20 \mathrm{~km}^{2}$.

Três fatores justificam a escolha da Bacia Hidrográfica do Rio Piancó para se aplicar o modelo ora proposto, ou seja: 
1) apresenta características hidrometeorológicas típicas do Norte-Nordeste; 2) possui boa densidade espacial de postos pluviométricos, que fornecem séries históricas de longa duração e 3) pode ser considerada de porte médio, representando bem as bacias contribuintes de reservatórios do Nordeste do Brasil, que possuem áreas de 200 a $15.000 \mathrm{~km}^{2}$.

\section{Dados}

Neste estudo foram considerados valores da vazão média mensal referente à estação fluviométrica de Piancó, cedidos pela (ANA, 2007), e valores de precipitação média mensal de cinco postos pluviométricos: Piancó, Santana dos Garrotes, Nova Olinda, Itaporanga e Boa Ventura, obtidos junto à (AESA, 2007). O período de análise compreende janeiro de 1964 a dezembro de 2003, totalizando 120 meses de observação, enquanto a avaliação referente à qualidade dos dados foi feita por inspeção visual analisando-se a consistência e o tamanho das séries.

A altura média de precipitação em uma área específica é necessária em muitos tipos de problemas hidrológicos; portanto, para sua determinação existem vários métodos, como: o método aritmético, o método das isoietas e o método de Thiessen; deste modo, o primeiro método citado foi considerado para o cálculo da média da precipitação dos cinco postos pluviométricos estudados no âmbito da bacia hidrográfica do rio Piancó.

\section{RNA proposta}

As RNAs utilizadas neste trabalho foram do tipo "MultiLayer Perceptron” (MLP) com três camadas. A camada de entrada de cada rede não faz processamento, ou seja, não se atribui a ela funções de ativação; ela simplesmente envia os dados de entrada, modificados por um peso, para cada um dos neurônios da próxima camada; a segunda camada, única escondida em cada rede neural, é composta de neurônios com função de ativação sigmóide e a camada de saída é formada por neurônios com função linear.

A forma funcional de uma RNA é determinada pela sua arquitetura, isto é, RNA com arquiteturas diferentes significam ajustes de funções distintas; portanto, neste estudo se pretende utilizar diversas arquiteturas a fim de escolher aquela que melhor prediga as vazões médias mensais da bacia em estudo. A metodologia adotada na investigação da arquitetura da RNA foi a de variar o número de neurônios na camada de entrada, o número de neurônios e a função de transferência na camada intermediária.

A relação entre um conjunto de entrada e saída foi representada por três modelos distintos que apresentam variações nos dados de entrada, em que o primeiro modelo mostra, como variáveis de entrada, as precipitações médias mensais dos seguintes postos pluviométricos: Piancó, Santana dos Garrotes, Itaporanga, Boa Ventura e Nova Olinda enquanto o segundo modelo diz respeito às mesmas entradas do primeiro modelo, com exceção do posto de Piancó, e o terceiro modelo apresenta, como dados de entrada, a média da precipitação nos cinco postos estudados. Para todos os modelos a variável de saída é sempre a vazão média mensal na estação fluviométrica de Piancó.
Para cada modelo criou-se uma RNA com 5, 10 e 15 neurônios na camada intermediária, com variação entre as funções de transferência sigmóide tangente hiperbólica (tan-sig) e sigmóide logarítmica (log-sig) nesta mesma camada totalizando 18 RNA distintas.

Em todas as RNAs, o treinamento foi realizado utilizando-se a técnica de otimização de Levenberg-Marquardt. A motivação pela utilização deste método no treinamento das RNAs se justifica não só por se tratar de uma ótima técnica para aproximação de relações não-lineares mas também por ser rápida e já ter produzido bons resultados, segundo Lima \& Ferreira Filho (2003) e Sperb et al. (1999) no treinamento de RNAs com propósitos semelhantes aos aqui estudados.

Segundo Hagan \& Menhaj (1994), esta técnica de otimização é muito mais eficiente que outras, quando se treinam redes que têm até poucas centenas de parâmetros (pesos e ruídos), provocando uma convergência mais rápida e resultados com maior precisão. Demuth \& Beale (1998) compararam o desempenho de vários algoritmos de treinamento em determinado problema e mostraram que o algoritmo de Levenberg - Marquardt é amplamente superior aos demais, pois atinge a convergência em menor tempo, com um número menor de iterações e menor número de operações com ponto flutuante.

Além da forma funcional da RNA considerou-se, durante o processo de treinamento, a influência da inicialização dos pesos, em que todas as RNAs foram inicializadas seis vezes. Outra característica importante é a extensão das séries de dados, que está relacionada com a quantidade de dados utilizados para o treinamento e validação das RNAs. Anmala et al. (2000) acreditam que, quanto maior for o tamanho da amostra de dados melhor será a generalização do problema. Em um problema chuva-vazão mensal, Lima \& Ferreira Filho (2003) utilizaram 456 dados para sua solução, enquanto Elshorbagy et al. (2000) empregaram apenas 50 para treinamento e validação para uma previsão de vazão anual. Para este estudo foram utilizados 120 dados, os quais foram separados em 72 valores para treinamento, 24 valores para validação e 24 valores para teste, correspondentes a 60, 20 e $20 \%$, respectivamente.

Antes do início do treinamento todos os dados de entrada foram normalizados e no final de cada treinamento, com os pesos e vieses ajustados, a RNA foi simulada para gerar resultados. Obtiveram-se 120 resultados que correspondem a dois tipos de arquitetura, com dados de entrada não normalizados e dezoito tipos de arquitetura com dados de entrada normalizados. Todas as respostas foram armazenadas em planilha Excel, convertendo os valores normalizados para valores não-normalizados; logo em seguida, todas as RNAs foram reinicializadas e a rede novamente treinada.

Cada resposta resultou de uma combinação diferente entre o número de entradas da RNA, o número de neurônios na camada intermediária, a função de transferência da camada intermediária e a inicialização dos pesos.

O processo de criação, treinamento e simulação da RNA, foi desenvolvido no software MATLAB. Como um sistema iterativo e linguagem de programação para computação técnica e científica em geral, o MATLAB permite a construção 
de “bibliotecas” de funções, denominada “toolboxes”, que o tornam apto a resolver classes particulares de problemas (Hanselman \& Littlefield, 1999). A “toolbox” de Redes Neurais do MATLAB possui ampla versatilidade e flexibilidade, haja vista que o seu uso possibilita a aplicação dos mais variados tipos de redes neurais além de permitir a modificação de redes já existentes, como alterações no número de camadas ou mesmo de algoritmos de treinamento com uma facilidade particular de inserção.

Foram totalizados 120 resultados correspondentes a 20 diferentes arquiteturas de RNAs. Para melhor compreendê-los, eles foram divididos em treinamento, validação e teste. Adotaram-se, na nomenclatura das arquiteturas de RNAs, as convenções que seguem. Todas as RNAs são identificadas por sete caracteres, em que o primeiro caractere identifica a rede pela letra ' $\mathrm{R}$ ', o segundo se refere à normalização dos dados de entrada, identificada pelas letras ' $S$ ', sem normalização, e 'C', com normalização; já o terceiro caractere diz respeito ao modelo utilizado, representado por uma numeração que varia de um a três; ele identifica o número de entradas e quais são as entradas; enfim, os caracteres quatro e cinco se referem ao número de neurônios da camada intermediária; por exemplo, o número 05 significa que a RNA possui cinco neurônios na camada intermediária; por sua vez, o sexto caractere mostra a função de transferência utilizada, representada pelas letras ' $T$ ', quando a função é sigmóide tangente hiperbólica, e 'L', quando a função é sigmóide logarítmica. Por fim, o último caractere se refere à inicialização e é representada por uma numeração que varia de um a seis; a inicialização um, por exemplo, significa a primeira inicialização para uma RNA em particular. Duas RNAs com um primeiro conjunto de pesos, com inicialização um, não apresentam os mesmos valores até porque as RNAs são diferentes, com número de pesos diferentes.

A opção em variar a arquitetura não apenas em termos da camada intermediária mas, também, em relação à camada de entrada possibilita, além de novas formas funcionais, a avaliação da sensibilidade da RNA em função das variáveis de entrada. A proposta de criar modelos e variar o número de neurônios na camada intermediária segue os mesmos moldes do trabalho de Lima \& Ferreira Filho (2003).

\section{Índices de desempenho}

Para se avaliar o desempenho de todas as RNAs utilizaram-se três estatísticas: Coeficiente de determinação $\left(\mathrm{R}^{2}\right)$, Coeficiente de Eficiência (E) e Erro Padrão da Estimativa (EPE).

i) Coeficiente de determinação: $O$ quadrado do coeficiente de correlação de Pearson é chamado coeficiente de determinação ou simplesmente $\mathrm{R}^{2}$; é uma medida da proporção da variabilidade de uma variável que é explicada pela variabilidade de outra. É pouco comum que se tenha uma correlação perfeita $\left(\mathrm{R}^{2}=1\right)$ na prática, porque existem muitos fatores que determinam as relações entre variáveis, na vida real. A Eq. 1 expressa o coeficiente de correlação de Pearson.

$$
\mathrm{R}=\frac{\mathrm{N} \Sigma(\mathrm{QoQc})-\sum \mathrm{Qo} \Sigma \mathrm{Qc}}{\sqrt{\left[\mathrm{N} \Sigma \mathrm{Qo}^{2}-(\Sigma \mathrm{Qo})^{2}\right]\left[\mathrm{N} \Sigma \mathrm{Qc}^{2}-(\Sigma \mathrm{Qc})^{2}\right]}}
$$

em que:

$$
\begin{aligned}
& \text { Qo - vazão observada, } \mathrm{m}^{3} \mathrm{~s}^{-1} \\
& \text { Qc - vazão calculada, } \mathrm{m}^{3} \mathrm{~s}^{-1} \\
& \mathrm{~N} \text { - número de observações }
\end{aligned}
$$

ii) Coeficiente de eficiência: Definido por Nash \& Sutcliffe (1970), este coeficiente tem sido utilizado por diversos pesquisadores na avaliação de modelos hidrológicos e na quantificação dos constituintes da água, para estimação de sua qualidade, Moriasi et al. (2007). Valores do coeficiente de eficiência maiores ou iguais a zero indicam melhor performance do modelo. A Eq. 2 expressa este coeficiente.

$$
\mathrm{E}=1-\frac{\sum(\mathrm{Qo}-\mathrm{Qc})^{2}}{\sum(\mathrm{Qo}-\overline{\mathrm{Qo}})^{2}}
$$

em que:

$$
\begin{aligned}
& \text { Qo - vazão observada, } \mathrm{m}^{3} \mathrm{~s}^{-1} \\
& \text { Qc - vazão calculada, } \mathrm{m}^{3} \mathrm{~s}^{-1} \\
& \text { Q̄o - é a média da vazão observada, } \mathrm{m}^{3} \mathrm{~s}^{-1}
\end{aligned}
$$

iii) Erro padrão da estimativa: O erro padrão da estimativa estipula o desvio médio entre os valores observados e os calculados de vazão; ele informa, de modo aproximado, quão grandes são os erros de estimativa em relação aos dados da amostra. EPE é medido na unidade de vazão; o que se busca é conseguir o menor valor possível do erro padrão da estimativa. O EPE é expresso pela Eq. 3.

$$
\mathrm{EPE}=\sqrt{\frac{\sum(\mathrm{Qo}-\mathrm{Qc})^{2}}{\mathrm{n}-1}}
$$

em que:

$$
\begin{aligned}
& \text { Qo - vazão observada, } \mathrm{m}^{3} \mathrm{~s}^{-1} \\
& \text { Qc - vazão calculada, } \mathrm{m}^{3} \mathrm{~s}^{-1} \\
& \mathrm{n} \text { - número de observações }
\end{aligned}
$$

Essas estatísticas foram calculadas para todos os valores gerados pelas RNAs, dividindo-se esses dados em treinamento, validação e teste. Os resultados foram armazenados em planilha Excel.

\section{RESULTADOS E DISCUSSÃO}

Dos 120 resultados obtidos, apenas os 24 melhores foram selecionados para análise. O critério de seleção das melhores arquiteturas foi o de avaliar o desempenho de generalização da RNA através de análises estatísticas entre os dados calculados e os observados para o período de teste. Para uma primeira avaliação considerou-se o coeficiente de determinação com valores maiores ou iguais a 90\%; esses resultados são apresentados na Tabela 1.

Observa-se, analisando-se as 24 arquiteturas selecionadas na Tabela 1, que a melhor arquitetura apresentada foi a RC305T3, com valor de 0,97 para o coeficiente de determinação; todas as arquiteturas utilizam o modelo três com dados de entrada normalizados; grande parte das arquiteturas apresenta cinco neurônios na camada intermediária; a função de transferência log-sig é apresentada em quinze arquiteturas enquanto a função tan-sig aparece em nove 
Tabela 1. Melhores arquiteturas considerando-se o coeficiente de determinação com valores maiores ou iguais a 90\%, para o período de teste

\begin{tabular}{|c|c|c|c|c|c|c|c|c|c|}
\hline & \multicolumn{3}{|c|}{ Treinamento } & \multicolumn{3}{|c|}{ Validação } & \multicolumn{3}{|c|}{ Teste } \\
\hline & $R^{2}$ & $E$ & EPE & $\mathrm{R}^{2}$ & $E$ & EPE & $\mathrm{R}^{2}$ & $E$ & EPE \\
\hline RC305T3 & 0,82 & 0,80 & 7,41 & 0,88 & 0,82 & 7,48 & 0,97 & 0,02 & 18,26 \\
\hline RC310L4 & 0,88 & 0,78 & 7,63 & 0,87 & 0,85 & 6,94 & 0,96 & $-0,51$ & 22,63 \\
\hline RC310L5 & 0,94 & 0,94 & 4,11 & 0,51 & 0,49 & 12,67 & 0,96 & $-1,27$ & 27,71 \\
\hline RC310T6 & 0,91 & 0,91 & 4,99 & 0,78 & 0,75 & 8,89 & 0,96 & $-0,21$ & 20,24 \\
\hline RC305L4 & 0,87 & 0,87 & 5,96 & 0,73 & 0,73 & 9,30 & 0,96 & $-3,43$ & 38,73 \\
\hline RC305T6 & 0,88 & 0,87 & 5,84 & 0,84 & 0,80 & 7,99 & 0,95 & $-1,03$ & 26,21 \\
\hline RC315L3 & 0,71 & 0,68 & 9,26 & 0,98 & 0,95 & 3,91 & 0,95 & 0,92 & 5,30 \\
\hline RC305T2 & 0,90 & 0,90 & 5,18 & 0,82 & 0,76 & 8,65 & 0,95 & 0,30 & 15,37 \\
\hline RC305L6 & 0,88 & 0,84 & 6,56 & 0,82 & 0,82 & 7,62 & 0,95 & $-0,15$ & 19,73 \\
\hline RC310L2 & 0,67 & 0,66 & 9,56 & 0,97 & 0,94 & 4,23 & 0,95 & 0,94 & 4,62 \\
\hline RC315T4 & 0,77 & 0,76 & 7,97 & 0,89 & 0,88 & 6,11 & 0,95 & 0,58 & 11,93 \\
\hline RC305L2 & 0,76 & 0,75 & 8,14 & 0,80 & 0,78 & 8,25 & 0,95 & $-0,50$ & 22,57 \\
\hline RC305L5 & 0,84 & 0,84 & 6,66 & 0,75 & 0,67 & 10,17 & 0,94 & 0,14 & 17,09 \\
\hline RC305L3 & 0,92 & 0,90 & 5,08 & 0,75 & 0,73 & 9,26 & 0,94 & $-0,26$ & 20,65 \\
\hline RC315L6 & 0,75 & 0,63 & 10,01 & 0,98 & 0,96 & 3,45 & 0,94 & 0,71 & 9,88 \\
\hline RC305L1 & 0,87 & 0,87 & 5,98 & 0,87 & 0,86 & 6,60 & 0,94 & 0,78 & 8,55 \\
\hline RC315L5 & 0,79 & 0,65 & 9,74 & 0,96 & 0,91 & 5,31 & 0,94 & 0,50 & 13,00 \\
\hline RC310L1 & 0,87 & 0,71 & 8,82 & 0,80 & 0,78 & 8,31 & 0,93 & $-0,96$ & 25,80 \\
\hline RC315L4 & 0,52 & 0,18 & 14,87 & 0,98 & 0,96 & 3,47 & 0,93 & 0,89 & 6,07 \\
\hline RC315T2 & 0,86 & 0,84 & 6,54 & 0,90 & 0,89 & 5,98 & 0,93 & 0,86 & 6,80 \\
\hline RC315L1 & 0,63 & 0,56 & 10,86 & 0,98 & 0,96 & 3,48 & 0,92 & 0,91 & 5,59 \\
\hline RC305T5 & 0,90 & 0,90 & 5,28 & 0,76 & 0,74 & 9,06 & 0,91 & 0,41 & 14,14 \\
\hline RC315T6 & 0,78 & 0,73 & 8,61 & 0,94 & 0,91 & 5,19 & 0,90 & 0,88 & 6,30 \\
\hline RC310T2 & 0,78 & 0,70 & 9,06 & 0,98 & 0,95 & 4,15 & 0,90 & 0,73 & 9,65 \\
\hline
\end{tabular}

arquiteturas e a arquitetura que apresentou maior frequência nas inicializações foi a RC305L.

Com base nas análises realizadas para a primeira avaliação, que considera apenas o coeficiente de determinação para o desempenho da arquitetura, nota-se que existe incoerência nos resultados. A melhor arquitetura apresenta cinco neurônios na camada intermediária e a função de transferência utilizada é a função tan-sig; observaram-se, nas demais análises, maior quantidade de arquitetura com cinco neurônios e com a função de transferência log-sig. Nas inicializações, por apresentar maior frequência, a melhor arquitetura é a RC305L. A análise da frequência de inicializações de uma arquitetura mostra a possibilidade da arquitetura representar o melhor resultado.

Como se considerou apenas o coeficiente de determinação, não se pode afirmar que essas características ou arquiteturas são as melhores para simular os dados de vazões médios observados na bacia hidrográfica e, em assim sendo, para se obter um padrão coerente nos resultados fez-se ne- cessário uma segunda avaliação considerando-se o erro padrão de estimativa com valores menores que sete unidades; este critério foi utilizado para observar os menores valores desse erro uma vez que, quanto menor seu valor melhor será o resultado; tais resultados são exibidos na Tabela 2.

A Tabela 2 mostra que a arquitetura com melhor resultado em todos os parâmetros estatísticos, foi a RC310L2, com coeficiente de determinação de 0,95 , coeficiente de eficiência de 0,94 , e erro padrão de estimativa de 4,62, considerando-se o período de teste; esta arquitetura possui as seguintes características: para os dados de entrada utilizou-se a arquitetura três com valores normalizados, a camada intermediária possui dez neurônios, a função de transferência utilizada foi a log-sig e o resultado foi obtido em uma segunda inicialização.

Analisando-se, de forma geral, a Tabela 2, tem-se que, dentre as seis arquiteturas selecionadas, apenas uma apresenta 10 neurônios na camada intermediária; as demais mostram 15 neurônios nessa camada; outra característica

Tabela 2. Melhores arquiteturas considerando-se o erro padrão de estimativa com valores menores que sete unidades, para o período de teste

\begin{tabular}{|c|c|c|c|c|c|c|c|c|c|}
\hline & \multicolumn{3}{|c|}{ Treinamento } & \multicolumn{3}{|c|}{ Validação } & \multicolumn{3}{|c|}{ Teste } \\
\hline & $\mathrm{R}^{2}$ & $E$ & EPE & $\mathbf{R}^{2}$ & $E$ & EPE & $\mathbf{R}^{2}$ & $\mathbf{E}$ & EPE \\
\hline RC310L2 & 0,67 & 0,66 & 9,56 & 0,97 & 0,94 & 4,23 & 0,95 & 0,94 & 4,62 \\
\hline RC315L3 & 0,71 & 0,68 & 9,26 & 0,98 & 0,95 & 3,91 & 0,95 & 0,92 & 5,30 \\
\hline RC315L1 & 0,63 & 0,56 & 10,86 & 0,98 & 0,96 & 3,48 & 0,92 & 0,91 & 5,59 \\
\hline RC315L4 & 0,52 & 0,18 & 14,87 & 0,98 & 0,96 & 3,47 & 0,93 & 0,89 & 6,07 \\
\hline RC315T6 & 0,78 & 0,73 & 8,61 & 0,94 & 0,91 & 5,19 & 0,90 & 0,88 & 6,30 \\
\hline RC315T2 & 0,86 & 0,84 & 6,54 & 0,90 & 0,89 & 5,98 & 0,93 & 0,86 & 6,80 \\
\hline
\end{tabular}


observada se refere à função de transferência e a função logsig que se apresentam com maior frequência. Se a análise for realizada por arquitetura, ter-se-á que a RC315L está presente em três inicializações, ou seja, 50\% dos resultados; já a arquitetura RC315T apresentou duas ocorrências mas indicou desempenho estatístico menos significativo que as arquiteturas analisadas anteriormente.

A fim de aumentar a confiabilidade dos resultados obtidos com as primeira e segunda avaliações, fez-se necessário analisar, em média, qual seria a melhor arquitetura; desta forma se efetuaram os cálculos das médias das inicializações dos parâmetros estatísticos utilizados em cada arquitetura obtendo-se vinte resultados, os quais se acham na Tabela 3.

Com os valores médios das inicializações dos parâmetros estatísticos, realizou-se uma análise na qual se consideraram, para o período de teste, os valores do coeficiente de determinação maiores ou iguais a $90 \%$. O resultado desta análise, mostrado na Tabela 4, indicou as três melhores arquiteturas. As arquiteturas RC305L e RC310L apresentaram valores negativos de $E$, indicando que sua eficiência não foi satisfatória o bastante para simular os dados de vazão, já que o critério utilizado por este coeficiente para o melhor desempenho diz respeito a valores maiores que zero (Nash \& Sutcliffe, 1970); no entanto, a arquitetura
RC315L apresentou o melhor desempenho se analisados os três parâmetros estatísticos, $\mathrm{R}^{2}$, E e EPE, com valores de 0,92, 0,77 e 8,29, respectivamente. Lima \& Ferreira Filho (2003) obtiveram, no estudo realizado no semiárido cearense, valores para o coeficiente de determinação de 0,86 na melhor arquitetura.

De forma geral, a arquitetura RC315L apresentou o melhor desempenho estatístico, com valor maior que 0,90 no coeficiente de determinação, maior que zero no coeficiente de eficiência e valor consideravelmente menor no erro padrão da estimativa. Esta arquitetura apresenta as seguintes características: para os dados de entrada utilizou-se o modelo três, com valores normalizados, a camada intermediária possui quinze neurônios e a função de transferência utilizada é a log-sig. Os resultados obtidos através da arquitetura, divididos em treinamento, validação e teste, são apresentados na Figura 1.

A Figura 1A mostra os resultados obtidos na fase de treinamento, notando-se que os valores estimados de vazão seguem o comportamento dos valores observados representando, com certa precisão, alguns picos, mas ora superestima uns ora subestima outros. O coeficiente de determinação, o coeficiente de eficiência e o erro padrão da estimativa, são apresentados na Tabela 4, com valores satisfatórios, tendo em vista que a rede está sendo treinada. Na Figura 1B os

Tabela 3. Média das inicializações dos parâmetros estatísticos em cada arquitetura

\begin{tabular}{|c|c|c|c|c|c|c|c|c|c|}
\hline & \multicolumn{3}{|c|}{ Treinamento } & \multicolumn{3}{|c|}{ Validação } & \multicolumn{3}{|c|}{ Teste } \\
\hline & $\mathrm{R}^{2}$ & $E$ & EPE & $\mathrm{R}^{2}$ & $E$ & EPE & $\mathbf{R}^{2}$ & $E$ & EPE \\
\hline RS105T & 0,18 & 0,17 & 14,98 & 0,14 & 0,12 & 16,69 & 0,09 & 0,02 & 18,13 \\
\hline RC105T & 0,93 & 0,93 & 4,25 & 0,92 & 0,90 & 5,42 & 0,44 & 0,27 & 15,34 \\
\hline RC110T & 0,94 & 0,94 & 3,61 & 0,88 & 0,86 & 6,10 & 0,37 & 0,18 & 16,54 \\
\hline $\mathrm{RC115T}$ & 0,95 & 0,94 & 3,28 & 0,91 & 0,89 & 5,62 & 0,42 & 0,34 & 14,77 \\
\hline RC205T & 0,92 & 0,92 & 4,46 & 0,92 & 0,89 & 5,68 & 0,77 & 0,38 & 14,39 \\
\hline RC210T & 0,89 & 0,86 & 5,33 & 0,90 & 0,89 & 5,90 & 0,67 & 0,43 & 13,44 \\
\hline RC215T & 0,94 & 0,90 & 4,23 & 0,87 & 0,85 & 6,83 & 0,72 & 0,56 & 12,02 \\
\hline RC305T & 0,82 & 0,81 & 6,90 & 0,83 & 0,79 & 8,05 & 0,88 & 0,19 & 15,56 \\
\hline RC310T & 0,72 & 0,62 & 9,65 & 0,89 & 0,85 & 6,58 & 0,79 & 0,50 & 12,41 \\
\hline RC315T & 0,84 & 0,82 & 6,85 & 0,87 & 0,83 & 6,93 & 0,80 & 0,71 & 9,59 \\
\hline RS105L & 0,23 & 0,21 & 14,55 & 0,16 & 0,13 & 16,57 & 0,05 & $-0,05$ & 18,87 \\
\hline RC105L & 0,94 & 0,94 & 3,74 & 0,89 & 0,86 & 6,23 & 0,59 & 0,45 & 13,37 \\
\hline RC110L & 0,97 & 0,97 & 2,54 & 0,92 & 0,91 & 5,18 & 0,53 & 0,44 & 13,31 \\
\hline RC205L & 0,94 & 0,94 & 3,96 & 0,92 & 0,91 & 5,22 & 0,79 & $-0,10$ & 17,94 \\
\hline RC210L & 0,93 & 0,92 & 4,02 & 0,83 & 0,79 & 7,65 & 0,71 & 0,57 & 11,81 \\
\hline $\mathrm{RC} 215 \mathrm{~L}$ & 0,90 & 0,89 & 5,17 & 0,81 & 0,79 & 8,02 & 0,72 & 0,55 & 12,28 \\
\hline RC305L & 0,85 & 0,85 & 6,40 & 0,79 & 0,76 & 8,53 & 0,95 & $-0,57$ & 21,22 \\
\hline RC310L & 0,73 & 0,57 & 9,58 & 0,82 & 0,78 & 7,83 & 0,90 & $-0,06$ & 16,63 \\
\hline RC315L & 0,71 & 0,59 & 10,17 & 0,95 & 0,93 & 4,43 & 0,92 & 0,77 & 8,29 \\
\hline
\end{tabular}

Tabela 4. Melhores arquiteturas pela média das inicializações, considerando-se o coeficiente de determinação com valores maiores ou iguais a $90 \%$, para o período de teste

\begin{tabular}{|c|c|c|c|c|c|c|c|c|c|}
\hline & \multicolumn{3}{|c|}{ Treinamento } & \multicolumn{3}{|c|}{ Validação } & \multicolumn{3}{|c|}{ Teste } \\
\hline & $R^{2}$ & $E$ & EPE & $\mathbf{R}^{2}$ & $E$ & EPE & $\mathrm{R}^{2}$ & $E$ & EPE \\
\hline RC305L & 0,85 & 0,85 & 6,40 & 0,79 & 0,76 & 8,53 & 0,95 & $-0,57$ & 21,22 \\
\hline RC315L & 0,71 & 0,59 & 10,17 & 0,95 & 0,93 & 4,43 & 0,92 & 0,77 & 8,29 \\
\hline RC310L & 0,73 & 0,57 & 9,58 & 0,82 & 0,78 & 7,83 & 0,90 & $-0,06$ & 16,63 \\
\hline
\end{tabular}



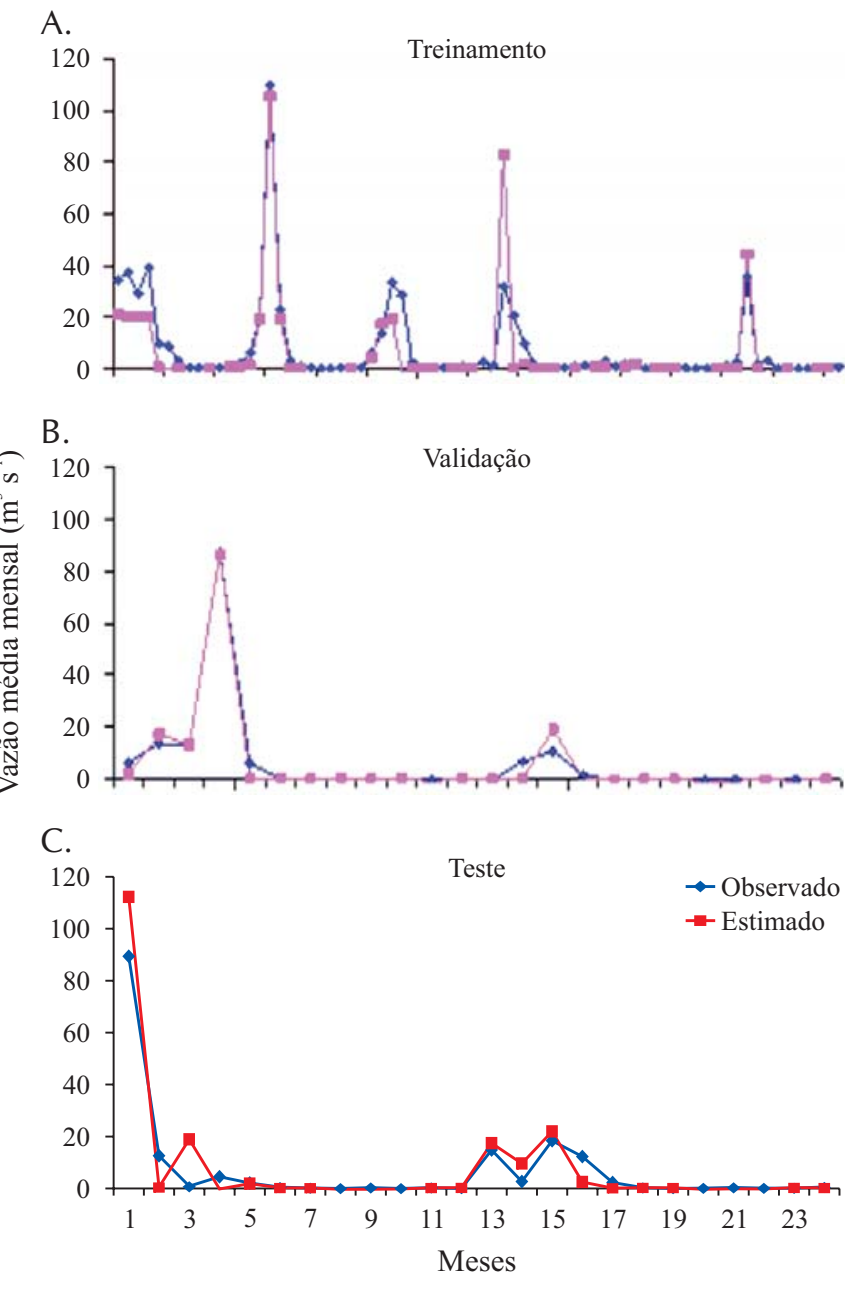

Figura 1. Resultados obtidos utilizando-se a arquitetura RC315L, divididos em três períodos, treinamento (A), validação $(B)$ e teste $(C)$

resultados se referem à fase de validação, os valores estimados de vazão apresentam o mesmo comportamento dos dados observados, superestimando o valor de vazão de pico no mês representado pelo número quinze. A Tabela 4 indica os parâmetros estatísticos analisados neste processo e se observam melhores resultados que no processo de treinamento. O processo de teste é apresentado na Figura 1C e mostra semelhança com o processo de validação, quanto aos parâmetros estatísticos utilizados para avaliar o desempenho. Nota-se que os valores estimados de vazão seguem o comportamento dos valores observados, com algumas imprecisões. No mês três há sobreestimativa no valor da vazão e nos meses treze e quinze, a estimativa é satisfatória representando bem o comportamento do pico de vazão dos dados observados.

\section{CONCLUSÕES}

1. Na avaliação em que se considera apenas o coeficiente de determinação no período de teste, a arquitetura RC305T3 obteve o melhor desempenho.

2. Dentre as 24 melhores arquiteturas, utilizando-se como entrada os valores normalizados da precipitação mé- dia de cinco postos pluviométricos, a melhor delas foi a RC305L, ressalvando-se que houve maior frequência de inicializações.

3. Pela análise de frequência de repetições, observa-se que a arquitetura RC305L e a função de transferência log-sig foram utilizadas mais vezes; e a arquitetura RC315L apresentou-se com maior frequência, com bons índices de desempenho. Considerando-se os valores médios dos parâmetros estatísticos das inicializações em cada arquitetura, concluise que a arquitetura RC315L foi a que obteve o melhor desempenho estatístico.

4. Em uma avaliação mais precisa, em que se consideram todos os índices de desempenho para o período de teste, a arquitetura RC310L2 indicou os melhores resultados.

5. A arquitetura RC315L, com base em RNA e na função de transferência log-sig com quinze neurônios na camada intermediária, pode ser utilizada para simular e prever as vazões médias mensais da Bacia Hidrográfica do Rio Piancó.

\section{LITERATURA CITADA}

AESA - Agência Executiva de Gestão das Águas do Estado da Paraíba. Disponível em <http://www.aesa.pb.gov.br>. 22 Set. 2007.

Almeida, R.; Barbosa, P. S. F. Previsão de secas hidrológicas com base em um modelo de redes neurais artificiais. In: Simpósio de Recursos Hídricos do Nordeste, 7, 2004, São Luís. ABRH. Anais CD Rom

ANA - Agência Nacional de Águas. Disponível em <http:// www.ana.gov.br>. 17 Set. 2007.

Anmala, J.; Zhang, B.; Govindaraju, R. S. Comparison of ANNs and emprirical aprroaches for predicting watershed runoff. Journal of Water Resources Planning and Management, v.126, n.3, p.156-166, 2000.

Barros, M. T. L.; Tsai, F. T. C.; Yang, S. L.; Lopes, J. E. G.; Yeh, W. W. G. Optimization of Large-Scale Hydropower System Operations. Journal of Water Resources Planning and Management, v.129, n.3, p.178-188. 2003.

Demuth, H.; Beale, M. Neural network toolbox for use with MATLAB - User's guide, version 3.0. The MathWorks, Inc., 1998. 742p.

Elshorbagy, A.; Simonovic, S. P.; Panu, U. S. Performance evaluation of artificial neural networks for runoff prediction. Journal of Hydrologic Engineering, v.5, n.4, p.424-427, 2000.

Favoreto, R. S.; Rohn, M. C.; Mine, M. R. M. A técnica de rede neural artificial aplicada na previsão de vazão. In: Simpósio Brasileiro de Recursos Hídricos e Simpósio de Hidráulica e Recursos Hídricos dos Países de Língua Oficial Portuguesa: Gestão de Recursos Hídricos - O desafio da prática, 5, 2001, Aracaju. Anais... Aracaju: ABRH. CD Rom

Flood, I.; Kartam, N. Neural networks in civil engineering I: principles and understanding, Journal Computational Civil Engineering, v.8, n.2, p.131-148, 1994.

Hagan, M. T.; Menhaj, M. Training feedforward networks with the Marquardt algorithm. IEEE Transactions on Neural Networks, v.5, n.6, p.989-993, 1994. 
Hamlet, A. F.; Huppert, D.; Lettenmaier, D. P. Economic value of long-lead streamflow forecasts for Columbia River hydropower. Journal of Water Resources Planning and Management, v.128, n.2, p.91-101, 2002.

Hanselman, D.; Littlefield, B. MATLAB 5 Versão do Estudante Guia do Usuário. São Paulo: MAKRON Books, 1999. 413p.

Lima, C. H. R.; Ferreira Filho, W. M. Análise de modelos de redes neurais aplicados ao processo chuva-deflúvio no semi-árido. In: Simpósio Brasileiro de Recursos Hídricos, 15, 2003, Curitiba. Anais... Curitiba: ABRH. CD Rom

Moriasi, D. N.; Arnold, J. G.; Liew, M. W. Van; Bingner, R. L.; Harmel, R. D.; Veith, T. L. Model evaluation guidelines for systematic quantification of accuracy in watershed simulations. Transactions of American Society oh Agricultural and Biological Engineers, v.50, n.3, p.885-900, 2007.

Muller, M.; Fill, H. D. Redes neurais aplicadas na propagação de vazões. In: Simpósio Brasileiro de Recursos Hídricos, 15, 2003. Curitiba. Anais... Curitiba: ABRH. CD Rom.

Nash, J. E.; Sutcliffe, J. V. River flow forecasting through conceptual models part 1 - A discussion of principles. Journal of Hydrology, v.10, n.3, p.282-290, 1970.

Olivo, A. A.; Silva, J. D. S.; Vijaykumar, N. L. Previsão de cheias fluviais usando redes neurais artificiais. In: Simpósio de Recursos Hídricos do Nordeste, 6, 2002. Maceió. Anais... Maceió: ABRH. CD Rom
Ramos, A. M.; Galvão, C. O. Estabilidade de redes neurais em modelagem hidrometeorológicas. In: Simpósio Brasileiro de Recursos Hídricos e Simpósio de Hidráulica e Recursos Hídricos dos Países de Língua Oficial Portuguesa: Gestão de Recursos Hídricos - O desafio da prática, 5, 2001, Aracaju. Anais... Aracaju: ABRH. CD Rom

Santos, C. C.; Pereira Filho, A. J. Modelagem hidrológica urbana por meio de redes neurais artificiais: uma aplicação para a Bacia do Rio Tamanduateí em São Paulo, SP. Revista Brasileira de Meteorologia, v.18, n.2, p.149-159, 2003.

Sarle, W. S. Neural networks and statistical models. Proceedings of the Nineteenth Annual SAS Users Group International Conference. Cary: SAS Institute, 1994. p.1538-1550.

Sousa, F. A. S.; Sousa, W. S. Rede neural aplicada ao processo chuva-vazão da Bacia Hidrográfica de Caraúbas - PB. In: Congresso Brasileiro de Meteorologia, 14, 2006. Anais... Florianópolis. SBMET. CD Rom

Sperb, R. M.; Modro, N. R.; Marcondes, P.; Foes, P. A.; Barcia, R. M.; Pacheco, R. C. S.; Tavares, G. Prevent: Protótipo de um sistema de previsão de enchentes baseado em redes neurais. In: Simpósio Brasileiro de Recursos Hídricos, 13, 1999. Anais... Belo Horizonte: ABRH. CD Rom

Tucci, C. E. M.; Collischonn, W. Previsão de vazão. In: Tucci, C. E. M.; Braga, B. (org.) Clima e recursos hídricos no Brasil. Porto Alegre: ABRH, 2003. p.281-348.

Villela, S.; Mattos, A. Hidrologia aplicada. São Paulo: McGrawHill, 1975. 244p. 